\title{
Thyroid function tests during carbimazole therapy
}

\author{
D. L. SCOTT \\ M.R.C.P. \\ M. A. TAYLOR
M.R.C.P.
}

D. J. TYMmS

M.R.C.P.

C. Chapman

Ph.D.

The Department of Nuclear Medicine, The General Infirmary, Leeds

\begin{abstract}
Summary
Changes in plasma thyroxine $\left(T_{4}\right)$, triiodothyronine $\left(T_{3}\right)$, free thyroxine index $\left(F_{4} I\right)$ and thyroid stimulating hormone were studied in 100 patients with Graves' disease treated with carbimazole. During therapy plasma $T_{3}$ concentrations were disproportionately high compared to those of $T_{4}$, the $T_{4}: T_{3}$ ratio was low, and many patients were clinically euthyroid with a normal plasma $T_{3}$ but low $T_{4}$ concentration. Although there was considerable individual variation in response, the order of response was always the same with plasma $T_{4}$ falling to normal or low levels before $T_{3}$. Plasma $T_{3}$ was the best indicator of clinical status and the best predictor of impending change; additional information of changes in thyroid status was obtained from plasma $T_{4}$ and $F_{4} I$ estimation, especially when these were followed sequentially. Single measurements of $\mathrm{T}_{4}$ or $\mathrm{FT}_{4} \mathrm{I}$ only are not recommended for assessing thyroid function during carbimazole therapy.
\end{abstract}

\section{Introduction}

Thyroid function tests are laboratory investigations which are frequently performed and their clinical relevance requires careful consideration. The assessment of thyroid function during carbimazole therapy is a common clinical problem and, although clinical judgement is important, biochemical thyroid function tests are often required. Estimations of the plasma thyroxine $\left(T_{4}\right)$ concentration or the free thyroxine index are recommended for this purpose (Britton et al., 1975; De Groot and Stanbury, 1975; Solomon, 1978).

Since triiodothyronine $\left(T_{3}\right)$ is metabolically important (Hoffenberg, 1973) and is over-produced in relation to $\mathrm{T}_{4}$ in untreated Graves' disease (Larsen, 1975; Nicoloff et al., 1972; Patel and Burger, 1973; Utiger, 1974) the value of using plasma $T_{4}$ levels to monitor carbimazole therapy is questionable. This study investigated the changes that occurred in plasma $T_{3}$ and $T_{4}$ concentrations during carbimazole therapy in 100 patients with Graves' disease, and evaluated their clinical relevance.

\section{Patients and methods}

One hundred patients with Graves' disease who were clinically thyrotoxic with raised plasma $T_{4}$ and $\mathrm{T}_{3}$ concentrations before treatment were included. Those who had had previous destructive therapy to the thyroid were excluded. All had at least 6 months' treatment with carbimazole, starting with doses of at least $40 \mathrm{mg}$ daily and reduced to a maintenance dose of 5-20 mg daily. Eighteen were consecutive patients with Graves' disease who were studied prospectively from 1973-75 (group A). This group had a mean age of $47 \cdot 2$ years (range 11-67) and 16 were female. In the first months of therapy they were seen every 1-2 weeks and thereafter every 1-2 months. Their clinical status was assessed, and recorded as thyrotoxic (slight, moderate, or severe), euthyroid, or hypothyroid (slight, moderate, or severe). At each visit blood was taken for estimations of plasma $T_{4}, T_{3}$, thyroid stimulating hormone (TSH) and the thyroid hormone distribution index (THDI) from which the free thyroxine index $\left(\mathrm{FT}_{4} \mathrm{I}\right)$ and the free triiodothyronine index $\left(\mathrm{FT}_{3} \mathrm{I}\right)$ were calculated.

A further 82 consecutive patients with Graves' disease attending a thyroid clinic between 1976-78 were studied retrospectively (group B). These patients were seen at regular intervals, but less frequently than those in group A. They were assessed in a similar manner to the patients in group $\mathbf{A}$ and had similar laboratory tests with the exception of plasma TSH levels which were not measured routinely. The patients in group B had a mean age of $44 \cdot 7$ years (range 15-76) and 74 were females. Patients who were pregnant or taking the contraceptive pill were not included in either prospective or retrospective studies.

A control series consisted of 150 hospital outpatients who had thyroid function tests as part of 
the routine assessment of conditions such as osteoporosis, diarrhoea, and alopecia. They were all clinically euthyroid, none was acutely ill or had been admitted as a medical or surgical emergency. They were selected sequentially, on an alphabetical basis, from patients attending in 1978 and had had estimations of plasma $T_{4}, T_{3}, F_{4} I$ and $F_{3} I$. Their mean age was 44.9 years (range 14-67) and 131 were female.

Plasma $T_{3}$ and $T_{4}$ were measured by pre-precipitated double antibody radioimmunoassays, the distribution index as described by MacDonald, Chapman and Franklin (1976) and TSH by postprecipitated double antibody radioimmunoassay using material supplied by the National Pituitary Agency (U.S.A.); using as a standard the 1st International reference preparation human TSH 68/38.

\section{Results}

Before treatment, plasma $T_{4}$ and $T_{3}$ concentrations correlated exactly with the clinical assessment. During the first 6 months of treatment the clinical assessment in groups $\mathrm{A}$ and $\mathrm{B}$ agreed with the plasma $\mathrm{T}_{3}$ on $64 \%$ of occasions, with the plasma $\mathrm{T}_{4}$ on $54 \%$ of occasions and with both $T_{4}$ and $T_{3}$ on $39 \%$ of occasions. Detailed results are shown in Fig. 1.

The frequent assessment of group A patients provided detailed information of the changes initiated by carbimazole therapy (Table 1). The mean plasma $T_{4}$ concentration fell to normal by 2 weeks (individual variation 1-5 weeks); the mean $\mathrm{FT}_{4} \mathrm{I}$ by 2 weeks (individual variation 1-4 weeks); the mean $\mathrm{T}_{3}$ by 5 weeks (individual variations 1-26 weeks) and the mean $\mathrm{FT}_{3} \mathrm{I}$ by 4 weeks (individual variations 2-26 weeks).

During treatment, $T_{4}$ entered the hypothyroid range in all the group $A$ patients (varying in time from 5-22 weeks); $T_{3}$ entered this range in 12 patients. A transient rise in TSH was observed in

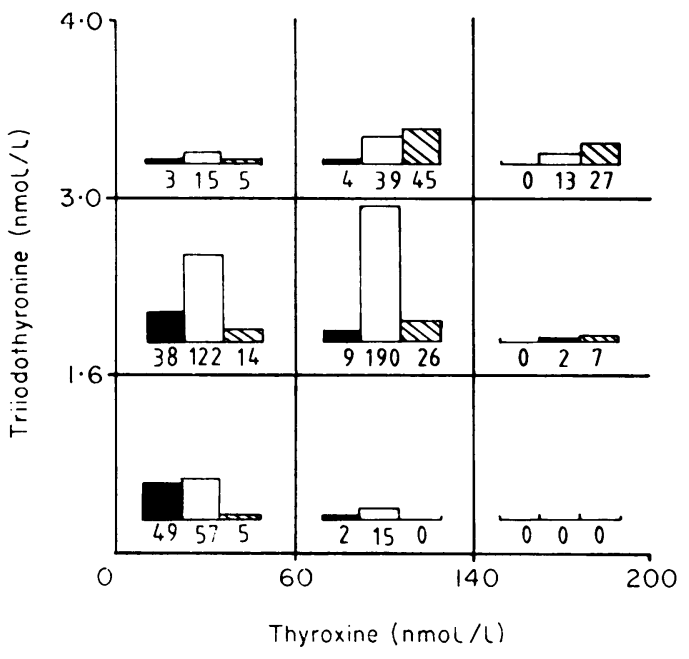

FIG. 1. The relationship of plasma $T_{3}$ and $T_{4}$ to clinical status. The assessments were made during the first 6 months' carbimazole therapy in groups $A$ and $B$. The results for plasma $T_{3}$ and $T_{4}$ are grouped as high, normal or low (reference ranges: $\left.T_{3} 1.6-3.0 \mathrm{nmol} / 1 ; T_{4} 60-140 \mathrm{nmol} / 1\right)$. The clinical assessment is given as thyrotoxic $(\mathbb{Z})$, euthyroid $(\square)$ or hypothyroid ( $\square$ ).

12 of the group A patients. These occasions were all preceded by a short period in which $\mathrm{T}_{3}$ or $\mathrm{FT}_{3} \mathrm{I}$ were in the hypothyroid range. Long periods during which $T_{4}$ and $\mathrm{FT}_{4} I$ were subnormal but $T_{3}$ and $F T_{3} I$ were normal did not raise TSH above the normal range. Thyrotrophin releasing hormone (TRH) tests were not performed systematically. However, 3 group A patients had this test when their basal TSH was normal but all other biochemical parameters were below the normal range; in each case the 20 min TSH response to TRH was exaggerated. Clinical changes were even more variable and lagged behind

TABLE 1. Carbimazole therapy: Initial changes in plasma $T_{4}$ and $T_{3}$ ( \pm s.e. mean)

\begin{tabular}{|c|c|c|c|c|c|c|c|c|c|c|c|c|}
\hline \multicolumn{13}{|c|}{ (18 Patients 1973/75: Group A) } \\
\hline \multirow{3}{*}{$\begin{array}{c}\text { Weeks of therapy } \\
\begin{array}{c}\text { Reference ranges } \\
0\end{array}\end{array}$} & \multicolumn{2}{|c|}{$\mathrm{T}_{4}(\mathrm{nmol} / \mathrm{l})$} & \multicolumn{2}{|c|}{$\mathrm{T}_{3}(\mathrm{nmol} / \mathrm{l})$} & \multicolumn{2}{|c|}{$\mathrm{T}_{4}: \mathrm{T}_{3}$ ratio } & \multicolumn{2}{|c|}{$\mathrm{FT}_{4} \mathrm{I}$} & \multicolumn{2}{|c|}{$\mathrm{FT}_{3} \mathrm{I}$} & \multicolumn{2}{|c|}{ TSH (i.u./l) } \\
\hline & 60 & 140 & & $-3 \cdot 0$ & & & & $-3 \cdot 2$ & $2 \cdot 5$ & $-5 \cdot 0$ & & 18 \\
\hline & $218 \cdot 8$ & $(7 \cdot 0)$ & $7 \cdot 35$ & $(0 \cdot 91)$ & $33 \cdot 8$ & $(3 \cdot 2)$ & $6 \cdot 15$ & $(0 \cdot 35)$ & $22 \cdot 10$ & $(2 \cdot 83)$ & $8 \cdot 7$ & $(0 \cdot 7)$ \\
\hline 1 & $166 \cdot 9$ & $(13 \cdot 6)$ & $5 \cdot 51$ & $(0 \cdot 32)$ & $30 \cdot 4$ & $(1.8)$ & $3 \cdot 84$ & $(0 \cdot 37)$ & $12 \cdot 3$ & $(1 \cdot 19)$ & $8 \cdot 8$ & $(0 \cdot 8)$ \\
\hline 2 & $122 \cdot 6$ & $(10 \cdot 2)$ & 4.03 & $(0 \cdot 34)$ & $29 \cdot 0$ & $(1 \cdot 6)$ & $2 \cdot 54$ & $(0 \cdot 26)$ & $8 \cdot 22$ & $(0.97)$ & $7 \cdot 3$ & $(0 \cdot 7)$ \\
\hline 3 & $106 \cdot 2$ & $(12 \cdot 5)$ & $3 \cdot 87$ & $(0 \cdot 34)$ & $26 \cdot 6$ & $(2 \cdot 3)$ & $2 \cdot 00$ & $(0 \cdot 22)$ & $6 \cdot 64$ & $(0 \cdot 66)$ & 9.9 & $(0.9)$ \\
\hline 4 & $95 \cdot 3$ & $(12 \cdot 6)$ & $3 \cdot 17$ & $(0.31)$ & $30 \cdot 1$ & $(1 \cdot 7)$ & $1 \cdot 48$ & $(0 \cdot 20)$ & $4 \cdot 89$ & $(0.48)$ & $9 \cdot 6$ & $(0.7)$ \\
\hline 5 & $84 \cdot 4$ & $(11 \cdot 7)$ & $2 \cdot 88$ & $(0 \cdot 26)$ & 26.6 & $(2 \cdot 2)$ & $1 \cdot 15$ & $(0 \cdot 13)$ & 3.92 & $(0 \cdot 35)$ & $9 \cdot 3$ & $(0 \cdot 6)$ \\
\hline 6 & 77.9 & $(17 \cdot 9)$ & $2 \cdot 77$ & $(0 \cdot 35)$ & $23 \cdot 4$ & (3.9) & 0.84 & $(0 \cdot 12)$ & $3 \cdot 24$ & $(0.32)$ & $12 \cdot 8$ & $(2.7)$ \\
\hline 7 & 54.9 & $(9 \cdot 1)$ & $2 \cdot 19$ & $(0 \cdot 26)$ & $24 \cdot 0$ & $(3.6)$ & 0.86 & $(0 \cdot 16)$ & $3 \cdot 34$ & $(0 \cdot 35)$ & $12 \cdot 4$ & $(2 \cdot 3)$ \\
\hline 8 & $44 \cdot 1$ & $(8.9)$ & 2.09 & $(0 \cdot 29)$ & $22 \cdot 5$ & $(3 \cdot 2)$ & 0.61 & $(0 \cdot 13)$ & 2.63 & $(0 \cdot 39)$ & $16 \cdot 7$ & $(6 \cdot 9)$ \\
\hline 9 & 44.9 & $(7 \cdot 2)$ & 1.82 & $(0 \cdot 26)$ & $22 \cdot 3$ & $(4 \cdot 4)$ & 0.72 & $(0 \cdot 22)$ & $2 \cdot 83$ & $(0 \cdot 61)$ & $19 \cdot 8$ & $(9 \cdot 1)$ \\
\hline 10 & $39 \cdot 6$ & (8.9) & $2 \cdot 37$ & $(0.43)$ & $18 \cdot 3$ & $(3 \cdot 7)$ & 0.62 & $(0.08)$ & 3.05 & $(0 \cdot 50)$ & $20 \cdot 4$ & $(7 \cdot 3)$ \\
\hline 11 & $56 \cdot 7$ & $(11 \cdot 7)$ & $2 \cdot 39$ & $(0.39)$ & $23 \cdot 7$ & $(3.5)$ & 0.65 & $(0 \cdot 10)$ & $3 \cdot 10$ & $(0.49)$ & 18.0 & $(7 \cdot 3)$ \\
\hline
\end{tabular}


all the biochemical parameters measured in this study.

The considerable individual variation in response to carbimazole is illustrated by the detailed results of 2 patients (Fig. 2). Both patients were females given initial doses of $40 \mathrm{mg}$ carbimazole daily. Patient W.S. had persisting ' $T_{3}$ toxicosis' during treatment, despite a fall in her plasma $T_{4}$ to hypothyroid concentrations. In contrast, patient D.S. had a rapid fall of both plasma $T_{4}$ and $T_{3}$ concentrations with a transitory rise in plasma TSH; her clinical status lagged behind the biochemical changes.

Five of the 100 patients had elevated plasma $T_{3}$ and $\mathrm{FT}_{3} \mathrm{I}$ concentrations persisting for at least 6 months after commencing treatment. Clinically they were all mildly thyrotoxic, but their plasma $T_{4}$ and $\mathrm{FT}_{4} \mathrm{I}$ concentrations had all rapidly fallen to normal or low levels. There was no evidence to suggest they were not taking carbimazole as prescribed and all responded to continuing high doses of carbimazole (30 $\mathrm{mg}$ or more daily). By one year they were all clinically and biochemically euthyroid.

The less frequent analysis of the 82 group B

D.S.

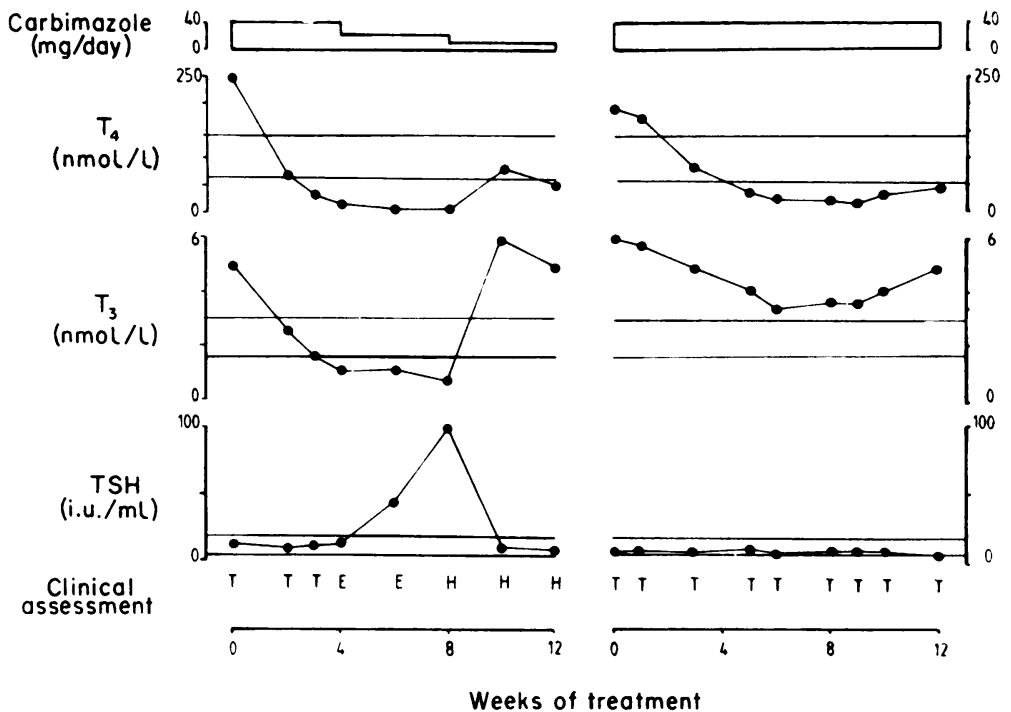

patients confirmed the findings seen in group A patients during carbimazole therapy. There was a rapid fall in $T_{4}$, followed by a slower and more variable fall in the concentration of $T_{3}$; clinical symptoms changed slower than both of these. The low $T_{4}: T_{3}$ ratio seen in untreated Graves' disease was not 'normalized' by carbimazole therapy, and remained considerably below that of the hospital control group (Table 2).

\section{Discussion}

The disproportionately high plasma $T_{3}$ and low $T_{4}: T_{3}$ ratio which is characteristic of untreated Graves' disease (Larsen, 1975), and occurs after radio-iodine and surgical treatment (Sterling et al., 1971), continues during carbimazole therapy. This is clearly shown by the results of this study and has been suggested from the results of a small survey by Linquette et al. (1978).

The response of the 18 patients in group $A$ showed that during carbimazole therapy different parameters of thyroid function changed at different rates; the order of response was $T_{4}, T_{3}, T S H$ and

Fig. 2. The variability of individual response to carbimazole in 2 females aged 48 years. Clinical assessment is given as thyrotoxic $(\mathrm{T})$, euthyroid $(\mathrm{E})$ or hypothyroid $(\mathrm{H})$.

TABLE 2. Plasma $T_{4}$ and $T_{3}$ ( \pm s.e. mean) in clinically euthyroid patients on carbimazole (from 82 patients $1976 / 78$ Group B)

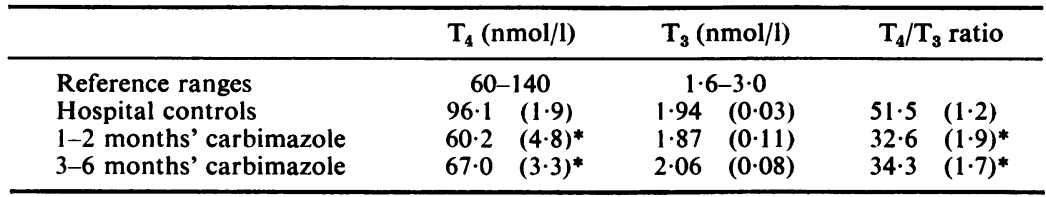

*Significantly different from hospital controls $(P<0 \cdot 001)$. 
lastly clinical assessment. Similar observations were made by Mortimer et al. (1977) in a study of 12 patients. There was marked individual variation in response; in any individual patient, changes in $\mathrm{T}_{3}, \mathrm{TSH}$, and clinical assessment could not be predicted from the $T_{4}$ values. In some patients, $T_{4}$ and $\mathrm{FT}_{4} \mathrm{I}$ were in the hypothyroid range and $\mathrm{T}_{3}$ in the hyperthyroid range. The divergence of $T_{3}$ and $T_{4}$ was most marked in the 5 patients with ' $T_{3}$ toxicosis' persisting for at least 6 months of treatment. This has previously been reported in a single case by Hollander et al. (1972) and in a small survey by Bellabarba and Tremblay (1972).

Plasma $T_{3}$ was the best indicator of thyroid status and the best predictor, in sequential series of results, of impending changes in clinical status. This conclusion is in keeping with the work of Shenkman, Mitsuma and Hollander (1973), who showed that TSH responsiveness correlated best with $T_{3}$ concentrations during acute propylthiouracil therapy. Similarly Hamada et al. (1978) have showed that during long-term treatment with anti-thyroid drugs the basal metabolic rate correlates best with plasma $T_{3}$.

Plasma $T_{3}$ estimations give the most clinically useful information to the physician during carbimazole therapy. Plasma $T_{4}$ and $\mathrm{FT}_{4} \mathrm{I}$ estimations give further information of changing thyroidal function and in conjunction with plasma $T_{3}$ estimations this may be clinically valuable. Serial estimations give the most useful information, especially when all parameters are measured; it is the authors' policy routinely to monitor these 3 indices during carbimazole therapy. Many clinicians and laboratory workers have been influenced by the work of Britton et al. (1975) who suggest the free thyroxine index is the measurement of choice to assess thyroid function. This is clearly not the case during carbimazole therapy and is unlikely to be true for diagnosing thyrotoxicosis since it is not always elevated in this situation. Although the costs of laboratory tests are important, the decision not routinely to measure $T_{3}$ concentrations restricts valuable clinical information, and may not actually save money (Chapman and Hayter, 1978). It is suggested that laboratories not routinely measuring $T_{3}$ should reconsider their policy. The dose schedule for carbimazole used in this series is one that is generally recommended for treating Graves' disease, although the variation between individuals in response to carbimazole shows that no single therapeutic regimen is appropriate for all patients.

\section{Acknowledgment}

We thank Dr C. J. Hayter for his help with this study.

\section{References}

Bellabarba, D. \& Tremblay, R. (1972) Serum patterns of thyroxine and triiodothyronine after the treatment of thyrotoxicosis with anti-thyroid drugs. International Journal of Clinical Pharmacology, 6, 18.

Britton, K. E., Quinn, V., Braun, B. L. \& Ekins, R. P. (1975) A strategy for thyroid function tests. British Medical Journal, 3, 350.

Chapman, C. \& Hayter, C. (1978) Cost of carrying out clinical diagnostic tests. British Medical Journal, 2, 830.

De Groot, L. J. \& Stanbury, J. B. (1975) The Thyroid and its Diseases, 4th Edn, p. 342. John Wiley \& Sons, New York.

Hamada, N., Miura, T., Ban, Y., Momotanu, N., Nishikwana, Y., Ohno, M., Mori, H., Kitabatake, S. \& Ito, K. (1978) Closer correlation between serum triiodothyronine and basal metabolic rate during antithyroid treatment in patients with Graves' disease. Endocrinologica japonica, $25,117$.

Hoffenberg, R. (1973) Triiodothyronine, Clinical Endocrinology, 2, 75 .

Hollander, C. S., Shenkman, L., Mitsuma, T. \& Asper, S. P. (1972) Triiodothyronine toxicosis developing during antithyroid drug therapy for hyperthyroidism. Johns Hopkins Medical Journal, 6, 184.

LARSEN, P. R. (1975) Thyroidal triiodothyronine and thyroxine in Graves' disease: correlation with presurgical treatment, thyroid status, and iodine content. Journal of Clinical Endocrinology and Metabolism, 41, 1098.

Linquette, M., Lefebvre, J., Benoit, G. \& Racadot, A. (1978) Les hormones thyroidiennes plasmatiques au cours du traitement des hyperthyroïdies par le carbimazole. Annals d'Endocrinologie, 39, 83.

MacDonald, R. G., Chapman, C. \& Franklin, H. (1976) Thyroid-pituitary response to cardiopulmonary by-pass. British Journal of Anaesthesia, 48, 225.

Mortimer, C. H , ANderson, D. C., Liendo-CH, P., Fisher, R., Chan, V., Self, M. \& Besser, G. M. (1977) Thyrotoxicosis: relations between clinical state and biochemical changes during carbimazole treatment. British Medical Journal, 1, 138.

Nicoloff, J. T., Low, J. C., Dussault, J. H. \& Fisher, D. A. (1972) Simultaneous measurement of thyroxine and triiodothyronine peripheral turnover kinetics in man. Journal of Clinical Investigation, 51, 473.

Patel, Y. C. \& Burger, H. G. (1973) Serum triiodothyronine in health and disease. Clinical Endocrinology, 2, 339.

Shenkman, L., Mitsum T. \& Hollander, C. S. (1973) Modulations of pituitary responsiveness to thyrotrophin releasing hormone by triiodothyronine. Journal of Clinical Investigation, 52, 205.

Solomon, D. H. (1978) The Thyroid (Ed by Werner, S. C. \& Ingbar, S. H.) 4th Edn, p. 818. Harper and Row, New York.

Sterling, K., Brenner, M. A., Newman, E. S., Odel, W. D. \& Bellabarba, D. (1971) The significance of triiodothyronine in the maintenance of euthyroid status after treatment of hyperthyroidism. Journal of Clinical Endocrinology, 33, 729.

Utiger, R. D. (1974) Serum triiodothyronine in man, Annual Review of Medicine, 25, 289. 